\title{
Construction of Virtual Ship Simulation Practical Training Platform
}

\author{
Rukai ZHANG \\ Department of Maritime, Tianjin Maritime College, Tianjin 300350, China \\ kaidesky@163.com
}

\begin{abstract}
Under the influence of current education mode for maritime majors of china, it is a prevalent problem for vocational college that the deficiency of teaching-training vessel. In order that the problems of teaching and learning caused by the lack of teaching-training vessel was solved, the method of building VR training platform was applied. Multigen Creator will be used to model, and after format conversion, the model will be driven by Unity3D to complete the virtual ship platform construction. With the cross-platform features of Unity3d, PC and mobile programming are respectively carried out to realize the network development of VR training platform. The stern and ship's bridge are the two key areas of virtual reality, and most of the professional knowledge involving hull structure is embodied in different means.
\end{abstract}

Key words: virtual simulation; virtual vessel; practical teaching; Multigen Creator; Unity3D

\section{INTRODUCTION}

The maritime technology major focuses on cultivating advanced marine technicians, who are in line with the national education policy and related international and domestic laws and regulations, and have a comprehensive quality, safety and environmental awareness, and have international competitiveness [1]. The teaching content is closely linked with the work, and the teaching process is an academic qualification. Education is also skill training. Comparing to the maritime professional education model represented by Britain, which is represented by ships, the model adopted by the higher vocational colleges in China, which had to study at school, to obtain a degree, at first, and then to work on board, makes the teaching process and the actual ship environment Detached. For the college does not have a teaching traineeship, the teaching equipment of the college is generally arranged and managed according to functional categories, and cannot reflect the systematicness and interdependence. Therefore, when the teaching content involves the overall layout of the ship and the mutual influence between the equipment, and so on, the existing implementation conditions cannot satisfy the teaching requirements.

At present, the application of virtual reality technology in marine education focuses on the training of collision avoidance rules and understanding of ship maneuverability, and the research on the related 
content of ship structure, equipment working principle and mutual influence among various components is still at an initial stage [2-3]. In order to provide students with a teaching environment closing to the actual ship, virtual simulation technology will be used to build a virtual ship laboratory, and graphics virtualization technology will be helpful to build a network training platform to reduce teaching difficulty, improve teaching quality, and save teaching costs.

The core content of the virtual ship training platform is the ship structure model. In order to reduce the hardware requirements, the model is simplified as much as possible on the premise of ensuring teaching needs. Multigen Creator[4] was chosen to create real-time 3D visual simulation model. The created model can be driven by the Unity3D [5-7] engine and can be rendered by a VR helmet to improve the immersion of the virtual environment. Graphics virtualization technology [8-9] can expand the virtual ship laboratories by LAN and realize interactive operation at any PC or mobile terminal.

The construction of a virtual ship training platform not only allows students to understand the ship structure, and participate in all aspects of work at a ship, effectively nurture the basic skills necessary for modern navigation, but also fully integrate the learning content into the entire process of safe navigation of ships, and intuitively builds a framework for students. An immersive ship simulation environment solves the problem that the study course of theory and practice are out of touch and their learning objectives are not clear. It also makes up for the insufficiency of the school's ability to provide students with enough opportunities to study and practice in real ships.

\section{THE CONSTRUCTION OF VR TRAINING PLATFORM, FOCUSING ON THE FUNCTION}

VR training platform takes the virtual ship as the carrier and integrates the teaching content with the actual ship. Each training represents an important part of an actual job or an independent activity. All content is divided rationally and goals are unified.

In order to ensure the rationality and completeness of the virtual ship structure, the virtual laboratory must not only realize the intuitive display of the ship structure, enable users to experience the process of boarding and deck walks, but also ensure a reasonable structure, reflect the specific equipment and the location of the ship's components and their relevance completely. For demonstrating the multi-degree-of-freedom motion characteristics of a ship, an appropriate water environment must be created for the ship. For the sake of meeting the teaching needs, it is also necessary to design a unique perspective for teaching content. On behalf of solving the limitation of the site's utilization of the virtual laboratory, a virtual ship training platform should be constructed to realize the parallel use of the virtual laboratory.

\section{DESIGN OF VIRTUAL SHIP TRAINING PLATFORM}

\section{the creation of ship model, based of Multigen creator}

Multigen creator is a software package developed by Multigen-Paradigm, Inc., USA, which is used to create real-time 3D models for visual simulation. The real-time three-dimensional (RT3D) database can be generated efficiently and optimally, and the software can be combined with the subsequent real-time simulation software closely, which helps to save the drawing overhead of the graphics workstation, guarantee the smoothness of the system and share the models by multiple terminals. 


\section{Data acquisition}

The main data required by Multigen creator modeling includes the coordinates and texture maps of the ship's main location. Because the ship belongs to a very large vehicle, the shape data is inconvenient to acquire directly through measurement. The coordinates of the main position of the ship's profile are imported from the ship design drawing in the DWG format. Due to the complex structure of the ship, data import needs to be completed step by step[10-11]. The ship's appearance under the main deck can be converted in the same way from the model line value of the ship.

Texture maps can be obtained by shooting on real ships. Plane and structure drawings should adopt different shooting methods. The plane should be backlit and obliquely shot as much as possible. The structure diagram should be selected at an angle that can highlight the structural features.

\section{Model constructing}

After obtaining the ship frame through data import in the earlier period, the ship structure details and the size of the equipment entity can be obtained through field measurement. The ship structure details and equipment entities should be consistent with the actual ship as far as possible, where the details need to be reflected (for example, the lantern of the compass). Other positions can be adjusted as needed. Before you import texture maps into Multigen creator, texture maps should be processed using Photoshop graphics processing software [4,12].

\section{Model driving}

The OpenFlight format 3D model files generated by Multigen creator can be called by many professional virtual reality development packages. Unity3D, which is fast in development and supports the release of multi-platform programs, is selected as a visual engine.

\section{The wave making}

Although Unity3D provides many tools for water surface rendering and water-boost, it mainly focuses on visual effects and does not correspond to the wave characteristics of specific sea areas. For the sake of ensuring the simulation accuracy, the marine environment where the ship is located can be obtained by generating a unidirectional random wave through the spectrum [13].

The effective wave slope can be expressed like this:

$$
\theta(t)=\sum_{i=1}^{N_{W}} \frac{\omega_{i}^{2}}{g} a_{i} \sin \left(\omega_{i} t+\varphi_{i}\right)
$$

And:

$$
a_{i}=\sqrt{2 S_{\text {wave }}\left(\omega_{i}\right) \delta \omega}
$$

The wave spectrum, recommended by the 15th ITTC, will be adopted

$$
S_{\text {wave }}\left(\omega_{i}\right)=\frac{A}{\omega_{i}{ }^{5}} \exp \left(-\frac{B}{\omega_{i}{ }^{4}}\right)
$$

And: 


$$
\begin{gathered}
A=172.75 \frac{H_{1 / 3}{ }^{2}}{T_{01}{ }^{4}} \\
B=\frac{691}{T_{01}{ }^{4}}
\end{gathered}
$$

$H_{1 / 3}$ : significant wave height, $T_{01}$ : mean wave period.

\section{Helmet roaming}

For providing a more immersive visual experience, the lab, based on Unity3D and HTC-VIVE, is equipped with 10 HTC-VIVE commercial 3D helmet virtual reality glasses [14]. In the training room, HTC-VIVE commercial version equipped with a handle device and a helmet. The experiencer can interact with the ship in the virtual scene through his own body movements and instantaneous movement, which not only enhances the sense of immersion, but also increases the interest of the learning process.

\section{APPLICATION OF THE VR LAB}

For the purpose of ensuring the integrity of the function of the virtual ship training platform and making sure the model construction can achieve the desired goal, the virtual bridge and virtual stern of the virtual ship model will be the focus of the model construction.

\section{Virtual bridge}

The bridge is the main place of work for the crew on deck. It is the space for the installation and storage of internal communication equipment, external communication equipment, navigational instruments, distress alert equipment, meteorological equipment, manoeuvring equipment connected to the cabin, and other necessary equipment. The space is relatively small. And the equipment placement must comply with relevant regulations. The VR Lab can describe the placement of related facilities and equipment in a flexible way. It can intuitively reflect the influence of various ship structures on the facilities and equipment. And the virtual bridge can provide a unique perspective that can't be achieved by real ship observation.

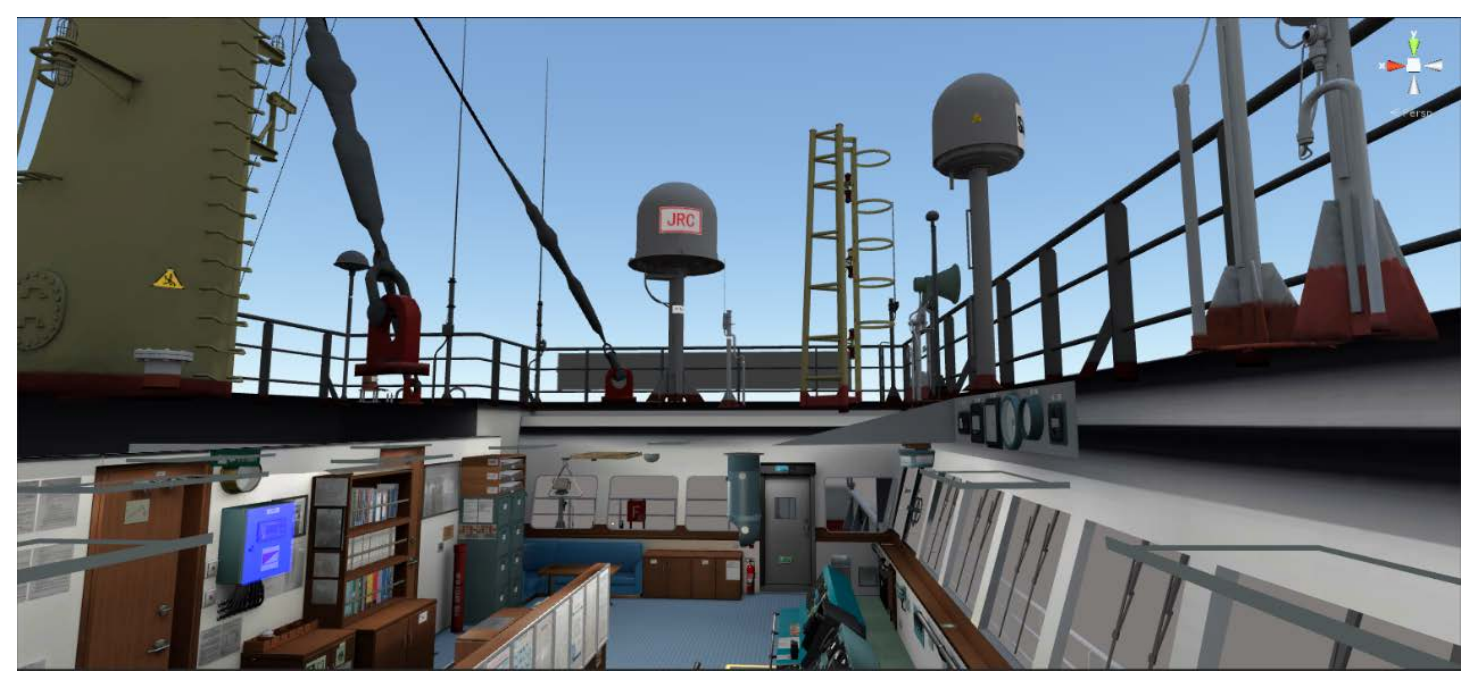

FIGURE 1. Virtual bridge on unique perspective 


\section{Virtual stern}

Propeller is underwater. It is not easy to apply the actual ship propeller working scene to teaching. The existing related resources are mainly obtained through animation simulation or real ship shooting. And neither of the two forms of teaching resources can achieve all-round multi-angle observations. At the same time, the video effect will also affect the clarity of the underwater environment. Using virtual modeling techniques, the hull-propeller-rudder attachment relationship can be presented.

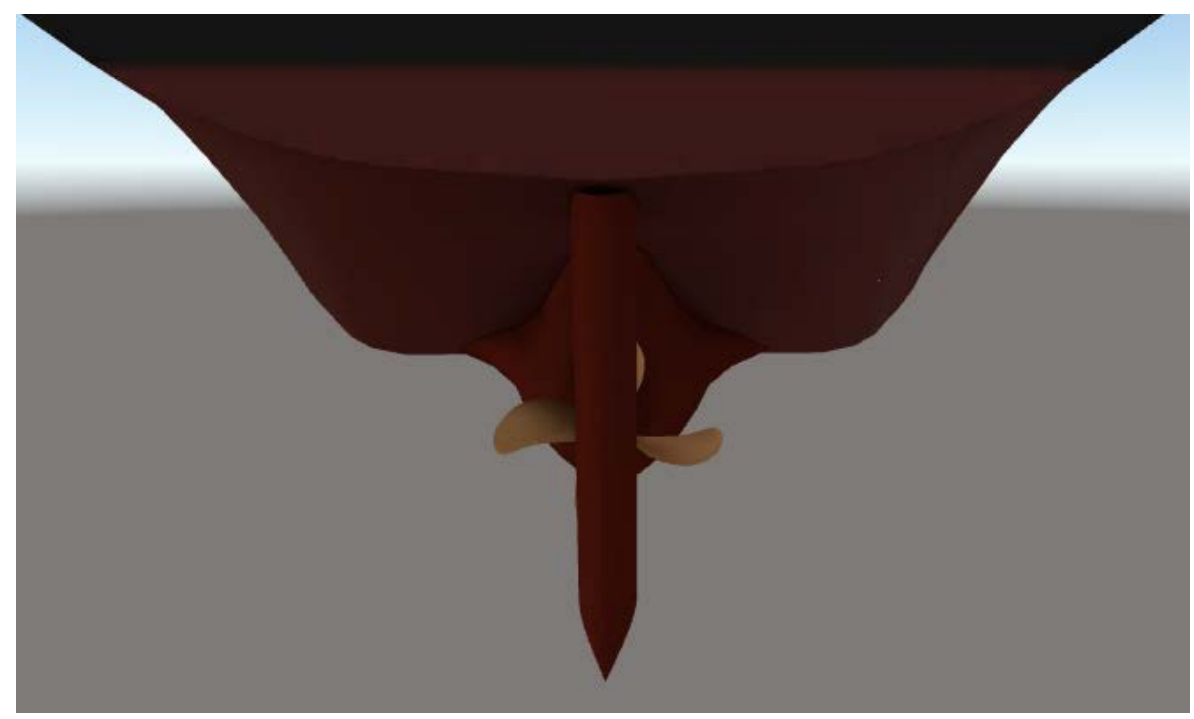

FIGURE 2. Virtual stern and hull-propeller-rudder attachment

\section{CONCLUSION}

Guided by the teaching needs, the ship model was completed using the Multigen creator. And the visual scene was driven by the Unity3D. With the help of the cross-platform support of Unity3D, PC-side and mobile-side programs were designed separately, and a VR training navigation platform was built.

\section{ACKNOWLEDGMENTS}

This work was financially supported by Tianjin City Jinnan District science and technology planning projects (20171508).

\section{REFERENCES}

1. Shi L.H, Wang P. Some Thoughts on Improving the English Proficiency of Maritime College Students. Navigation Education Research, 2002(04):75-77.

2. Hu X.M. Application of Virtual reality Technology in Classroom Teaching reform for Navigation Majors. Journal of Zhejiang Vocational College of Transportation, 2016(4):49-52.

3. Wang L, Zheng T. Research on Application of Virtual Reality Technology in Maritime Practice Teaching. Education Teaching Forum, 2016(44):183-184.

4. Meng X.M, Liu W.Q. MultiGen Creator Course. Beijing: National Defense Industry Press, 2005:126-132. 
5. Zhang G.T, Zhu W.Q. Virtual Laboratory Simulation based on Unity3D. China Computer \& Communication, 2017(3):30-32.

6. Zhu H.J. Virtual Roaming System Based on Unity3D. Computer Systems \& Applications, 2012, 21(10):36-39.

7. Abdullah N A S, Rusli N I A, Ibrahim M F. Mobile game size estimation: COSMIC FSM rules, UML mapping model and Unity3D game engine[C]// Open Systems. IEEE, 2015:42-47.

8. Jiang B.J, Wu J.M. Remote Sound Card and Graphics Card Virtualization Based on KVM. Computer Systems \& Applications, 2013, 22(09):75-80.

9. Zhang Z. Research on Direct Graphics Transmission Technology Based on KVM Virtualization. Software Guide, 2016, 15(10):142-144.

10. He H.Y. Practice in the Optimal Layout of Ship' s Cabin. Ship \& Ocean Engineering, 2007, 36(4):12-14.

11. Lu G P, Xue G H, Chen Z. Design and Implementation of Virtual Interactive Scene Based on Unity 3D[J]. Advanced Materials Research, 2011, 317-319:2162-2167.

12. Shao X.D. Creator Modeling Art. Xi'an : Xi'an University of Electronic Science and Technology Press, 2014 : 198-234.

13. Yang H.P, Sun J.G. Wave Simulation Based on Ocean Wave Spectrums. Journal of System Simulation, 2002, 14(9):1175-1178.

14. Lin Q. Design and Implementation of Virtual Reality Game Based on Unity3D and HTC-VIVE. Telecom World, 2017(3):43-44. 